\title{
Photonic RF and Microwave Photonic Channelizers based on Kerr Micro-combs
}

\author{
David Moss ${ }^{1}$
}

${ }^{1}$ Affiliation not available

December 6, 2021

\begin{abstract}
We review recent work on broadband RF channelizers based on integrated optical frequency Kerr micro-combs combined with passive micro-ring resonator filters, with microcombs having channel spacings of $200 \mathrm{GHz}$ and $49 \mathrm{GHz}$. This approach to realizing RF channelizers offers reduced complexity, size, and potential cost for a wide range of applications to microwave signal detection.
\end{abstract}

\section{Hosted file}

Channelizer J Sem authorea.pdf available at https://authorea.com/users/418067/articles/ 548066-photonic-rf-and-microwave-photonic-channelizers-based-on-kerr-micro-combs 